\title{
Desiccation in dewatering and strength development of high-density hard rock tailings
}

\author{
P. Simms Department of Civil and Environmental Engineering, Carleton University, Canada
}

S. Sivathayalan Department of Civil and Environmental Engineering, Carleton University, Canada

F. Daliri Department of Civil and Environmental Engineering, Carleton University, Canada

\begin{abstract}
The time for a freshly deposited layer of high-density tailings to reach a given water content and the contribution of desiccation to the geotechnical behaviour of the stack are complementary pieces of information. Generic modelling analyses to predict dewatering time, first presented at the 13th International Seminar on Paste and Thickened Tailings in 2010 (Paste 2010), are compared with a laboratory simulation of multilayer deposition and select field data. The multilayer experiment supports the finding of the generic modelling predictions: the rate of dewatering decreases over time, as evaporation can be supplied by water from the underlying pre-desiccated tailings. Geotechnical behaviour is discussed using results from simple shear and vane tests on samples with different degrees of desiccation and different levels of subsequent consolidation. Desiccation appears to substantially increase strength and imparts strain hardening behaviour to tailings even after they are re-saturated and consolidated. Substantial increases in strength occur well before the shrinkage limit is reached. Finally, the relevance of shear strength development to overall stack geometry and beach angle is briefly discussed.
\end{abstract}

\section{Introduction}

One of the potential advantages of cycling deposition of thickened or high-density tailings between different sections of an impoundment is the increase in density and shear strength imparted by desiccation. Cycling is achieved in the field through a variety of methods, such as deposition between different towers (formerly at the Bulyanhulu mine), changing the direction of deposition from a central point (Cooper et al., 2011), advancing a cone (McPhail and Brent, 2007), or alternating between spigots in deposition from a starter embankment. Knowing both the time required after deposition to achieve a target water content and the increase in shear strength imparted by desiccation to that target water content would facilitate appropriate assessment of the advantages of high-density tailings options early in a project's life. At present, the state of practice for both these numbers often uses rules of thumb that are of limited utility. For drying of thin layers, it is often assumed that the layer dries uniformly with depth at the potential rate; this is known not be true from both field measurements and laboratory experiments (Fisseha et al., 2010; Simms et al., 2007). A number of phenomena that might affect drying of a fresh layer of tailings are summarised in Figure 1. The interlayer interaction is particularly important for controlling the rate of drying.

For strength gain, it is often assumed that drying tailings to their shrinkage limit will impart a strain hardening response under shear, which will in turn prevent remobilisation of the tailings during earthquakes. While desiccation can produce a strain hardening response in the material, strain-hardening behaviour is not a guarantee against significant deformation. It is also commonly believed that the contribution of desiccation to stress history is the same as to the contribution of mechanical consolidation. This is not necessarily true (Kim et al., 2011).

The contribution of desiccation to strength is through stress history. That is, it is assumed that the desiccated layers of tailings are rewetted to the point that matric suction is low and does not contribute to strength. The stress history of a high-density tailings layer can be visualised by considering the paths in 
matric suction and the total stress space, as shown in Figure 2. The question is how the extent of desiccation influences the behaviour of subsequently re-saturated and consolidated tailings?

This paper presents a series of results (laboratory, field, and numerical) on both the contribution of desiccation to dewatering and the contribution of desiccation to strength gain. Both sets of data are discussed with respect to operational feasibility of high-density tailings systems.

Evaporation rate (weather, albedo, surface suction)

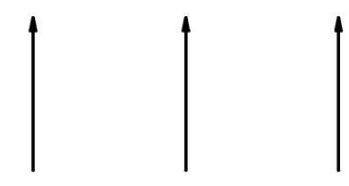

Effect of crusting? Cracking?

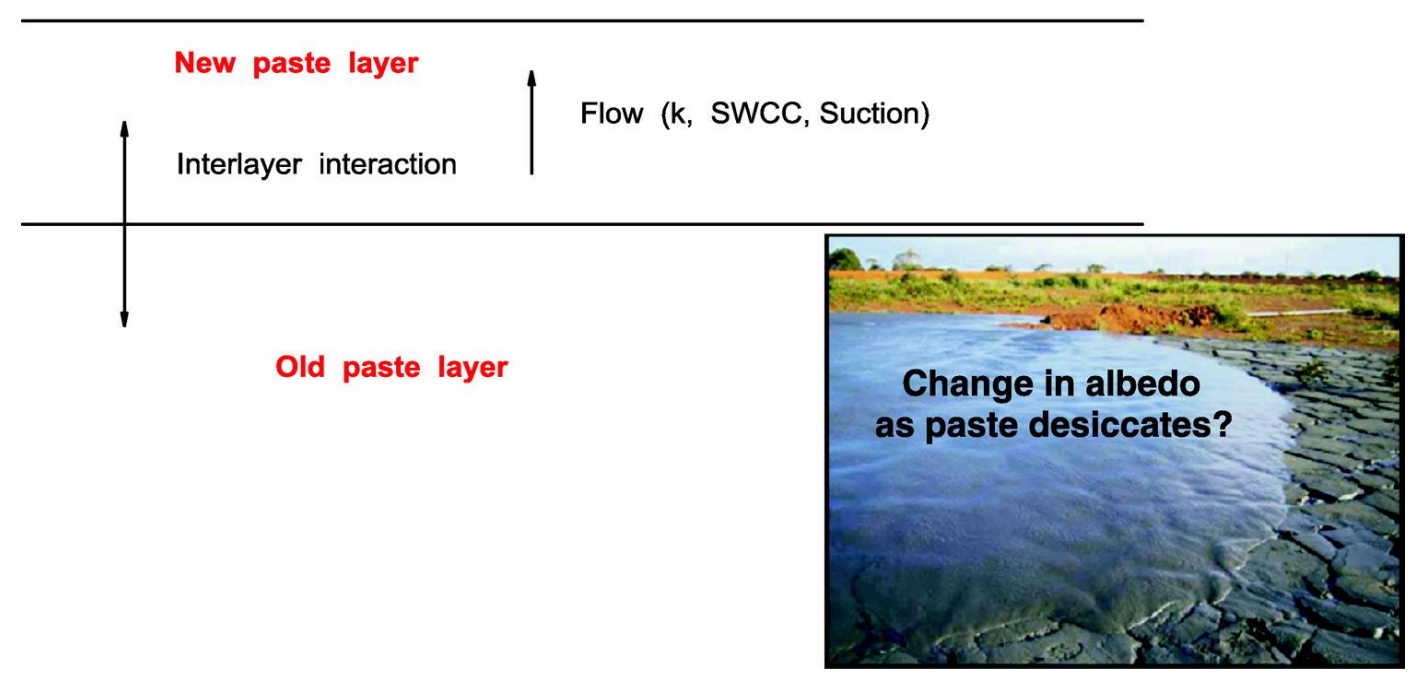

Figure 1 Phenomena affecting rate of dewatering of fresh layer of high-density tailings (Simms and Grabinsky, 2004)

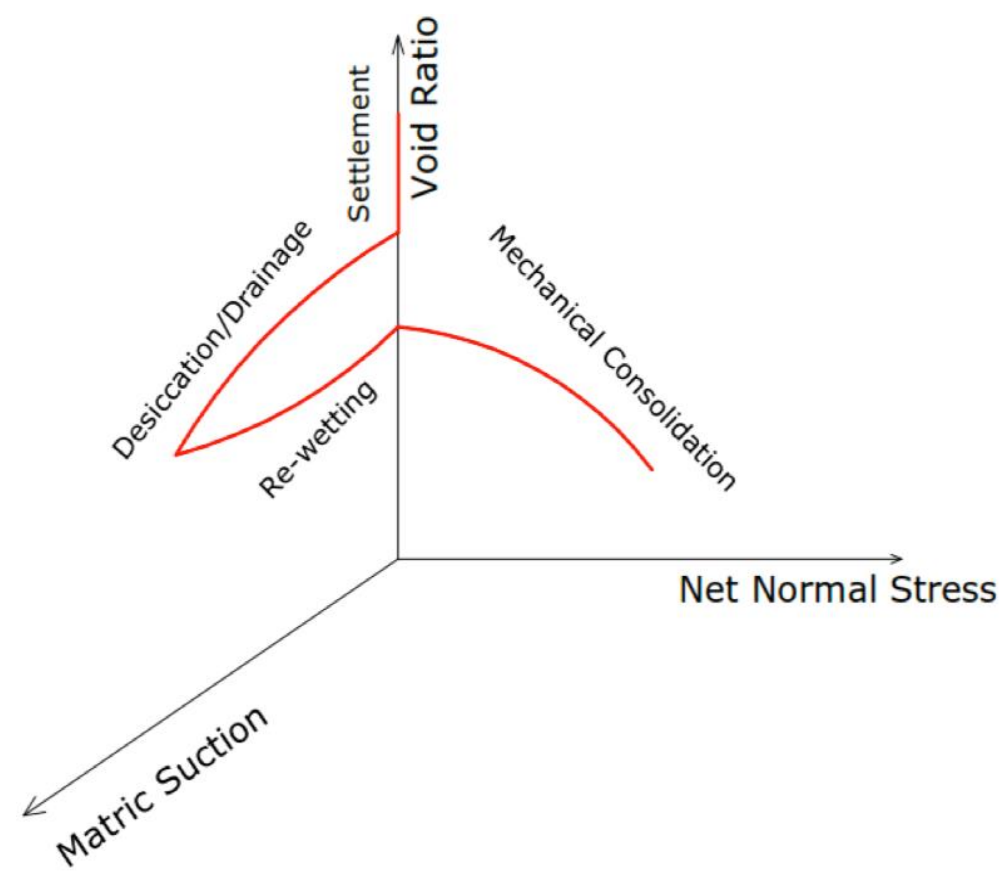

Figure 2 Conceptual stress history experienced by a layer of high-density tailings

during desiccation and subsequent burial by new tailings (Daliri et al., 2011) 


\section{$2 \quad$ Materials and methodology}

\section{$2.1 \quad$ Materials}

Tailings shipped from a gold mine had settled through vibration to water contents between $22-25 \%$ geotechnical gravimetric water content (GWC). Tailings were reconstituted using bleed water to $38 \%$ GWC ( $72 \%$ solids). The particle size distribution, shown in Figure 2, was determined by combination of sieve (wet technique) and hydrometer analyses results based on ASTM D 422-63 (2002). Liquid limit (LL), and plastic limit (PL) were $22.5 \%$ and $20 \%$, respectively (ASTM D4318, 2000). The shrinkage limit was $18 \%$. The specific gravity was 2.89 (ASTM D854, 2000). The mineralogy of the tailings included silicates (80\%), pyrite (11\%), calcite (5\%), and ankerite (4\%) (Bryan et al., 2010). The chemical analysis of the tailings liquid phase showed the concentration of important dissolved ionic species: sodium $(394 \mathrm{mg} / \mathrm{L})$, arsenic $(95.3 \mathrm{mg} / \mathrm{L})$, copper (126 mg/L), magnesium (2,010 mg/L), calcium (7,030 mg/L), and iron (31,100 mg/L) (Bryan et al., 2010).

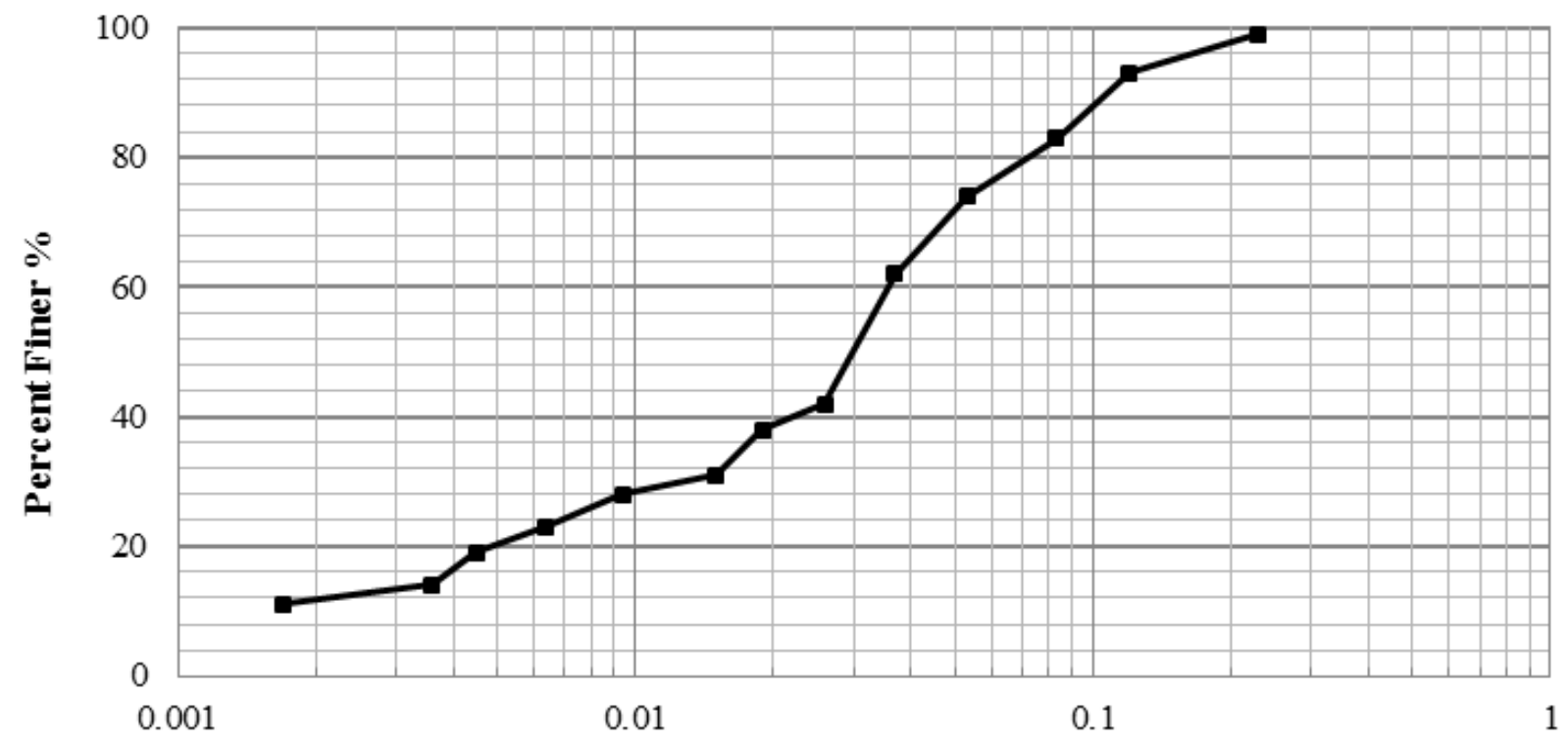

Grain Size, $\mathbf{m m}$

\section{Figure 3 Grain-size distribution of gold tailings}

\subsection{Physical simulation of multilayer deposition}

Tailings were sequentially deposited at $70 \%$ solids in five layers with initial thickness of $0.2 \mathrm{~m}$ (Layers 1, 2, 3, and 5) or $0.15 \mathrm{~m}$ (Layer 4: this was to provide some information on sensitivity of dewatering behaviour to layer thickness), into a steel reinforced plexiglass box with a $1 \mathrm{~m} \times 0.7 \mathrm{~m}$ plan area. The box was modular so as to minimise variation in the distance from the top of the tailings to the top of the box. The bottom half of the box is shown in Figure 4. The apparatus was mounted on load cells to measure water loss. Drainage was monitored out of the bottom using a tipping bucket. A geotextile was placed at the bottom of the box before placement of tailings. Evaporation was regulated by two fans placed on either side of the box. Relative humidity and temperature at the top edge of the box were monitored. Each layer was monitored using two or three volumetric water content sensors (EC-5 from Decagon), which also measured bulk electrical hydraulic conductivity and temperature. Three tensiometers (Model T5 from UMS) were installed with depth in each layer. Vertical displacement of the top tailings surface was measured using four ultrasonic-based distance sensors. The surface was sampled for gravimetric water and total suction.

The tailings were left to undergo two resaturation and drying cycles between Layers four and five. Also, a few hours before deposition of Layer five the tailings were wetted again to reduce matric suction to near zero. This was done to simulate deposition over tailings in a relatively wet state. 


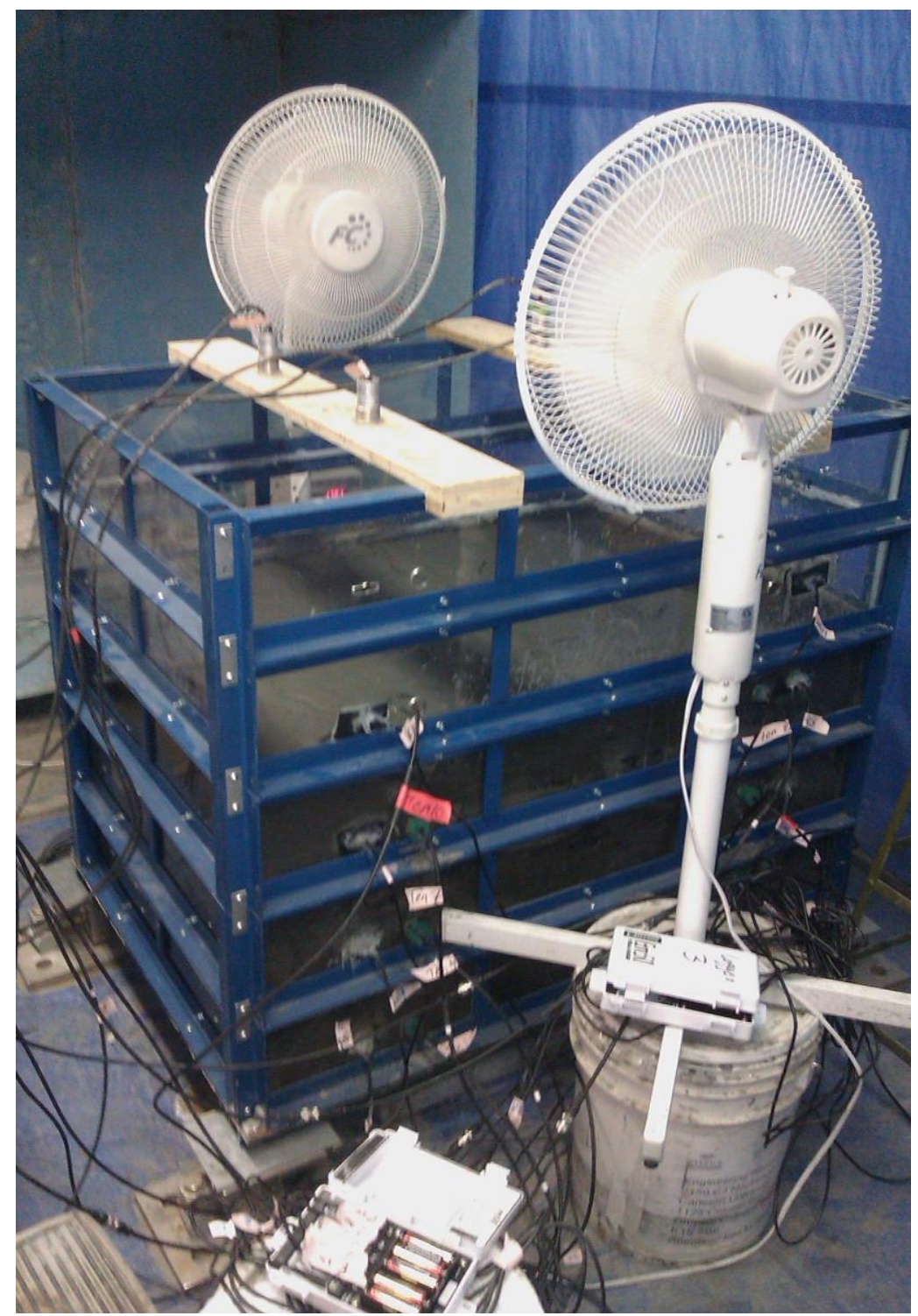

\section{Figure 4 Modular drying box, shown assembled to half its height}

\subsection{Modelling of dewatering}

Modelling of evaporation and flow within the drying box used the unsaturated flow software SVFlux, a commercial package from SoilVision. Void ratio is then related to water content through the shrinkage curve. The modelling methodology is explained in Simms et al. (2010), Fisseha et al. (2010), and Simms et al. (2007). Material parameters, such as the water retention curves (soil-water characteristic curves), saturated hydraulic conductivity, and relative hydraulic conductivity functions, are identical to the values used in Fisseha et al. (2010). The important and novel aspects of the modelling methodology are as follows:

1. Simulate the initial bleed water release by choosing an appropriate value for the storage parameter and the initial positive pore-water pressure distribution, essentially to force the model to generate the same amount of water that the tailings release due to settling (for these tailings, the post-settling water content is $\sim 30 \%$ geotechnical, or a solids concentration of $75 \%$ ).

2. Use different water-retention curves and saturated hydraulic conductivity values for fresh tailings and previously desiccated tailings.

Generic results using the same methodology and a range of likely parameters for hard rock tailings were presented in the proceeding of Paste 2010 (Simms et al., 2010). These results are compared with the drying box results and field measurements from two sites. 


\subsection{Simple shear and vane testing of desiccated-rewetted samples}

Two layers of tailings of thickness of about $10 \mathrm{~cm}$ are sequentially deposited in a cylindrical column with $25 \mathrm{~cm}$ diameter. The tailings were deposited at $70 \%$ solids (38\% geotechnical water content) and allowed to settle and desiccate to different values of water content, above and below the shrinkage limit $-30,28,25$, $23,19,17,12$ and $4 \%$ - all geotechnical. Two commercial fans were located on top of the column in order to accelerate desiccation. Drying of these and similar hard rock tailings typically results in a uniform profile of water content with depth, according to observations made by Fisseha et al. (2010) and Bryan et al. (2010). After desiccation was complete, the first layer of tailings was then overlaid with fresh tailings. The tailings were left for 12 hours to allow for re-saturation of the underlying sample, but before substantial evaporation could occur. Thin-wall tubes with the length-diameter ratio of 1.4 were used to obtain samples for strength testing. The water content of the desiccated and rewetted second layer at sampling was always greater than $21 \%$, and the degree of saturation varied between 0.95 and 0.90 . Extracted samples were then placed in the simple shear device subsequently consolidated under $50 \mathrm{kPa}, 100 \mathrm{kPa}$, and $200 \mathrm{kPa}$ consolidation pressures. Cyclic tests were conducted using a range of cyclic stress ratios $\left(\tau_{\max } / \sigma_{\mathrm{v}}^{\prime}\right)$ from 0.075 to 0.2 , but these are not reported here. Details of the simple shear device and a description of its theory can be found elsewhere (Al-Tarhouni et al., 2011).

A field vane was also used to test samples prepared in the same way by inserting the vane into the lower layer. Some results were also obtained on the desiccated layer before rewetting (and therefore before addition on the next layer).

\section{$3 \quad$ Results and discussion}

\section{1 $\quad$ Drying box, measured and modelled}

Dewatering during the multilayer deposition experiment is shown in terms of GWC (Figure 5); actual evaporation is calculated from total mass change minus drainage (Figure 6) and average void ratio of the topmost layer (Figure 7). Void ratio was calculated by using the non-contact displacement sensors, estimating crack volume by surface measurements, and assuming a triangular cross-section. By observation, any deformation of the previously deposited tailings due to the weight of the next layer was not detected. Cracks were assumed to only be contiguous across the top layers, and this was borne out during excavation of the test. Bench scale rewetting tests confirm that these tailings do not increase in volume when rewetted, but may experience a slight collapse (decrease in void ratio $<0.05$ ).

The pattern of overall dewatering behaviour is an increase in the time required to dry to a given water content as the number of layers increases. For example, the time required to get to $18 \%$ GWC (the shrinkage limit) occurs on Days 5, 16, 27, 37, and 71 for the first four layers, equivalent to dewatering times of $5,8,10,10$, and 13 . As noted in the methodology section, Layer four was smaller than the other layers $(15 \mathrm{~cm}$ compared to $20 \mathrm{~cm})$. The increase in dewatering time occurs despite the increase in the rate of settling - that is the initial phase of dewatering from $~ 70 \%$ to $75 \%$ solids ( $38 \%$ to $30 \%$ GWC). The rate of settling increases as this water is readily absorbed by the underlying tailings; this can occur even as the tailings are flowing down the beach (Mizani et al., 2010).

Actual evaporation rates are calculated from total mass lost minus the drainage. The drainage was insignificant in all layers except for the first, where it comprised $20 \%$ of the mass loss during the first 48 hours. The pattern of actual evaporation is relatively repeatable from test to test, with the potential evaporation rate varying from $10 \mathrm{~mm} /$ day to $8 \mathrm{~mm} /$ day. Void ratios decrease in conjunction with water contents immediately after deposition; the minimum void ratio measured was slightly higher $(0.65)$ than the shrinkage limit test (0.6).

The Layer five drying results, along with two sets of field data, one from Bulyanhulu (Simms et al., 2007) and one from Musselwhite Mine (Kam et al., 2011), are compared with generic predictions made for dewatering of a $0.2 \mathrm{~m}$ layer deposited at 70\% solids made in Simms et al. (2010). The generic predictions are obtained directly from that paper. It can be seen that both sets of field data seem to conform to the 
behaviour predicted by the modelling - a relatively quick initial rate of dewatering followed by a decreasing rate of dewatering. Note that the generic predictions for $0.5 \mathrm{~m}$ and $0.2 \mathrm{~m}$ layers are very close in their longterm behaviour. The measured data for Layer five dries faster than the predictions, but this is reasonable given the smaller amount of underlying tailings $(<1 \mathrm{~m})$ compared to the generic predictions that used five metres or larger (Simms et al., 2010).

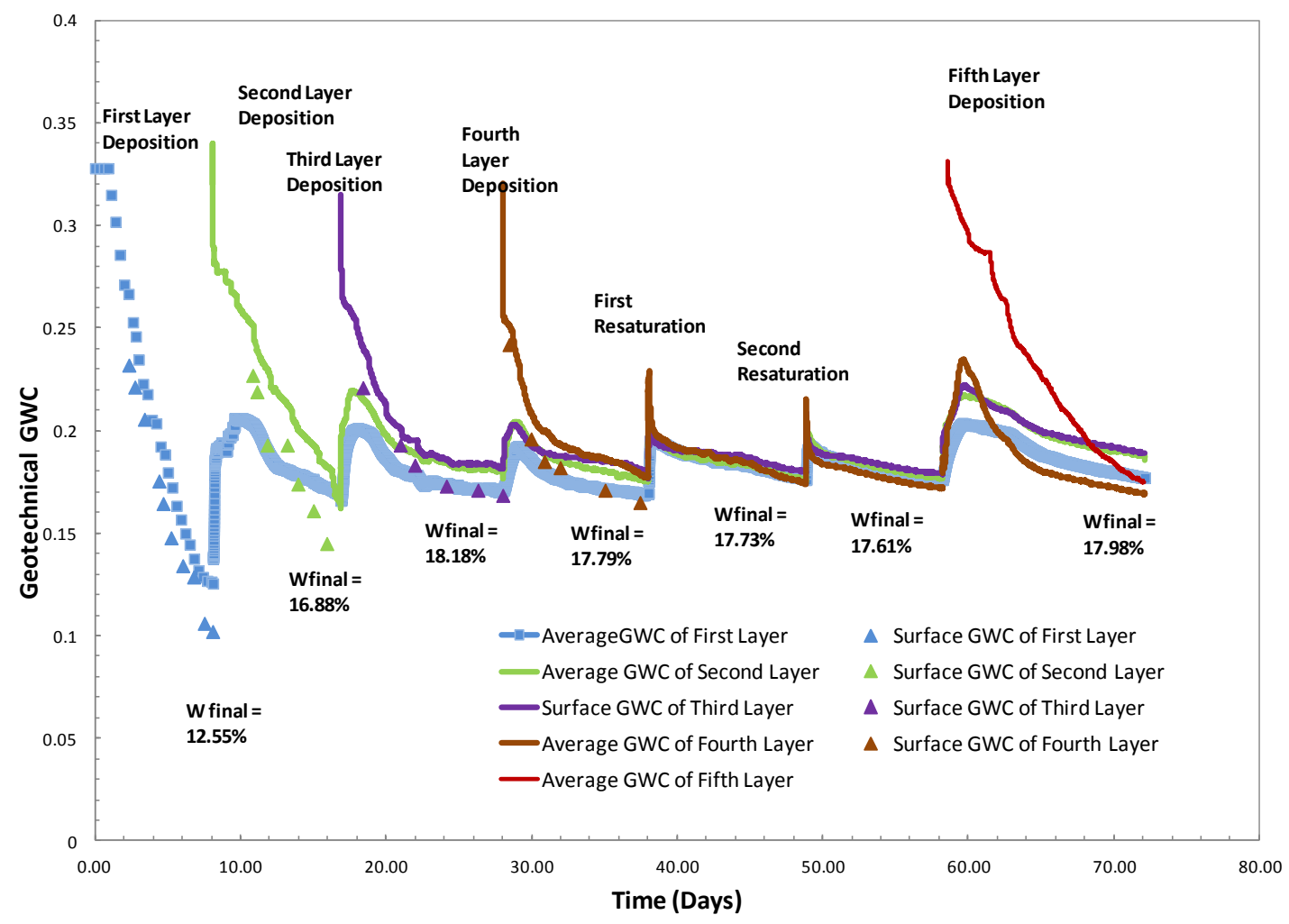

Figure 5 Gravimetric water contents in multilayer deposition experiment

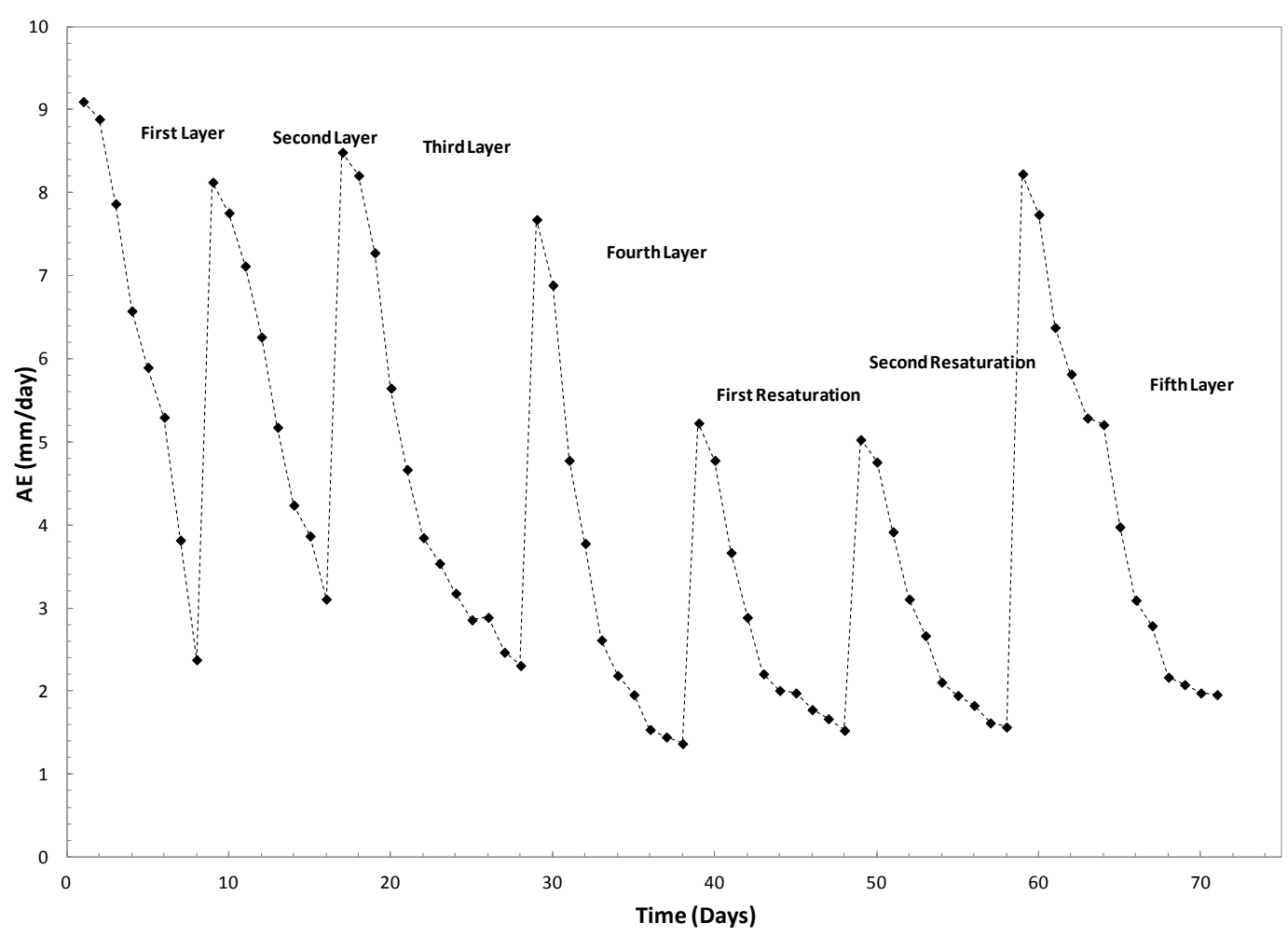

Figure 6 Measured daily evaporation rates in multilayer deposition experiment 


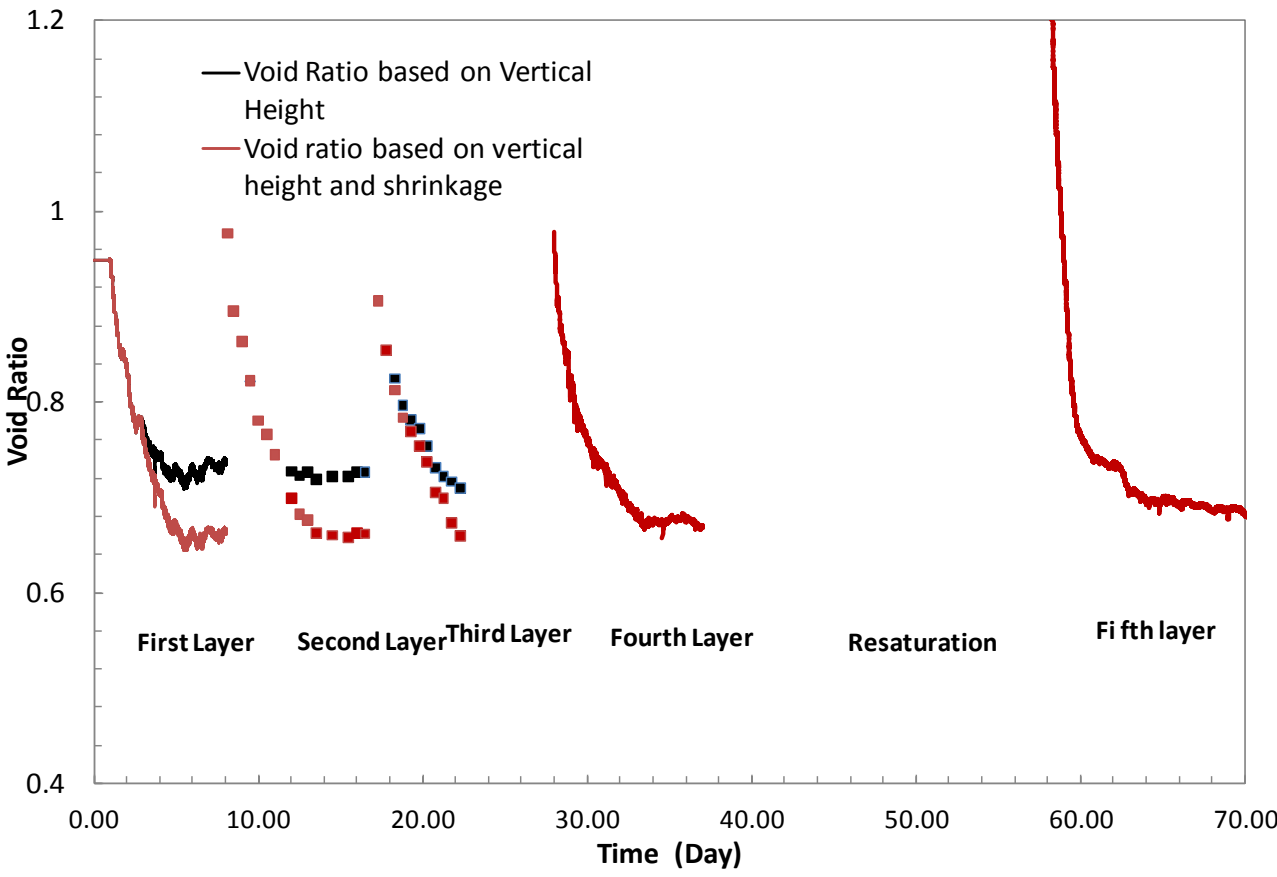

Figure 7 Void ratio in multilayer deposition test

The model predictions are compared with measurements for actual evaporation (AE) for Layers one and five (Figure 8), and for overall dewatering for Layer five (Figures 9 and 10). Predictions of AE are quite reasonable, as the cumulative evaporation are somewhat under-predicted for Layer one and somewhat over-predicted for Layer five. The dewatering behaviour of Layer five conforms in principal to the predictions of Simms et al. (2010), as the underlying tailings act as a reservoir for water during the later stages of dewatering, slowing down the rate of dewatering. As shown in Figure 9 in the model and in Figure 5 in the data, the underlying tailings do lose water to the top layer. In terms of overall dewatering behaviour, the model provides again a reasonable prediction. The discrepancy in the first two days might be due to the assumption of constant saturated hydraulic conductivity in the model, while in reality the hydraulic conductivity might change one or two orders of magnitude. However, as long the endpoint of the initial settling phase is correctly simulated, there is no influence on the prediction of longer term drying behaviour.

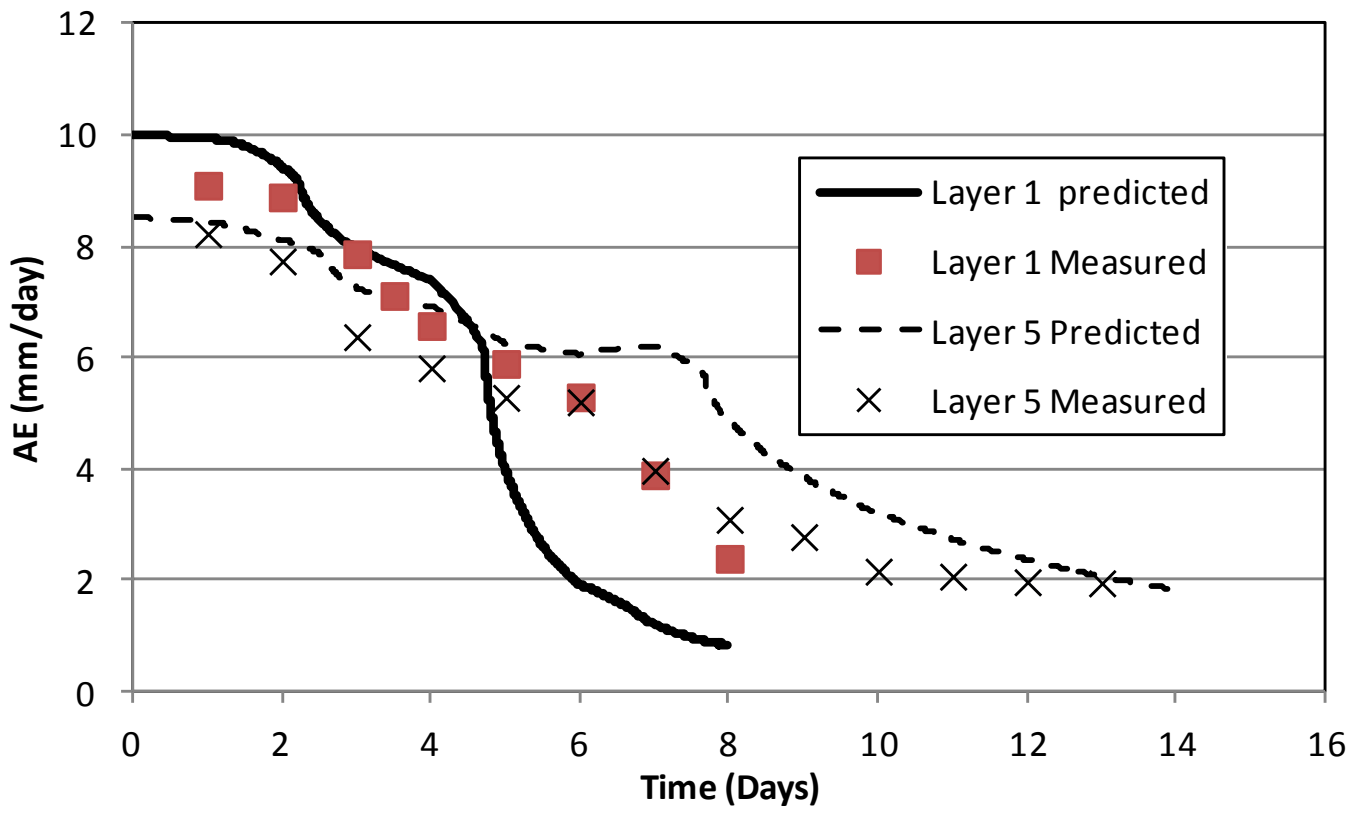

Figure 8 Measured and predicted AE for Layers one and five 


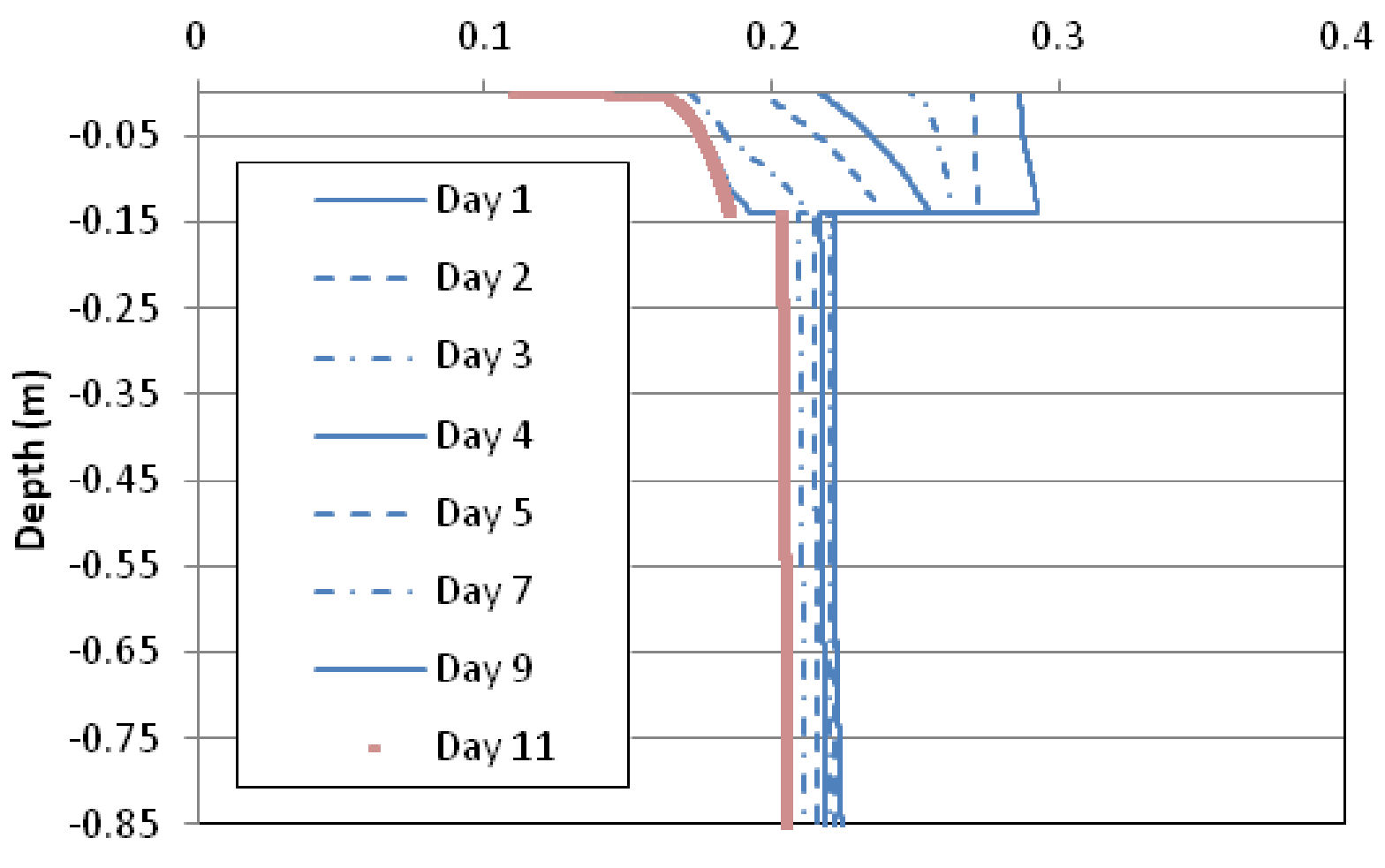

\section{Geotechnical GWC}

Figure 9 Predicted evolution in water content for Layer five

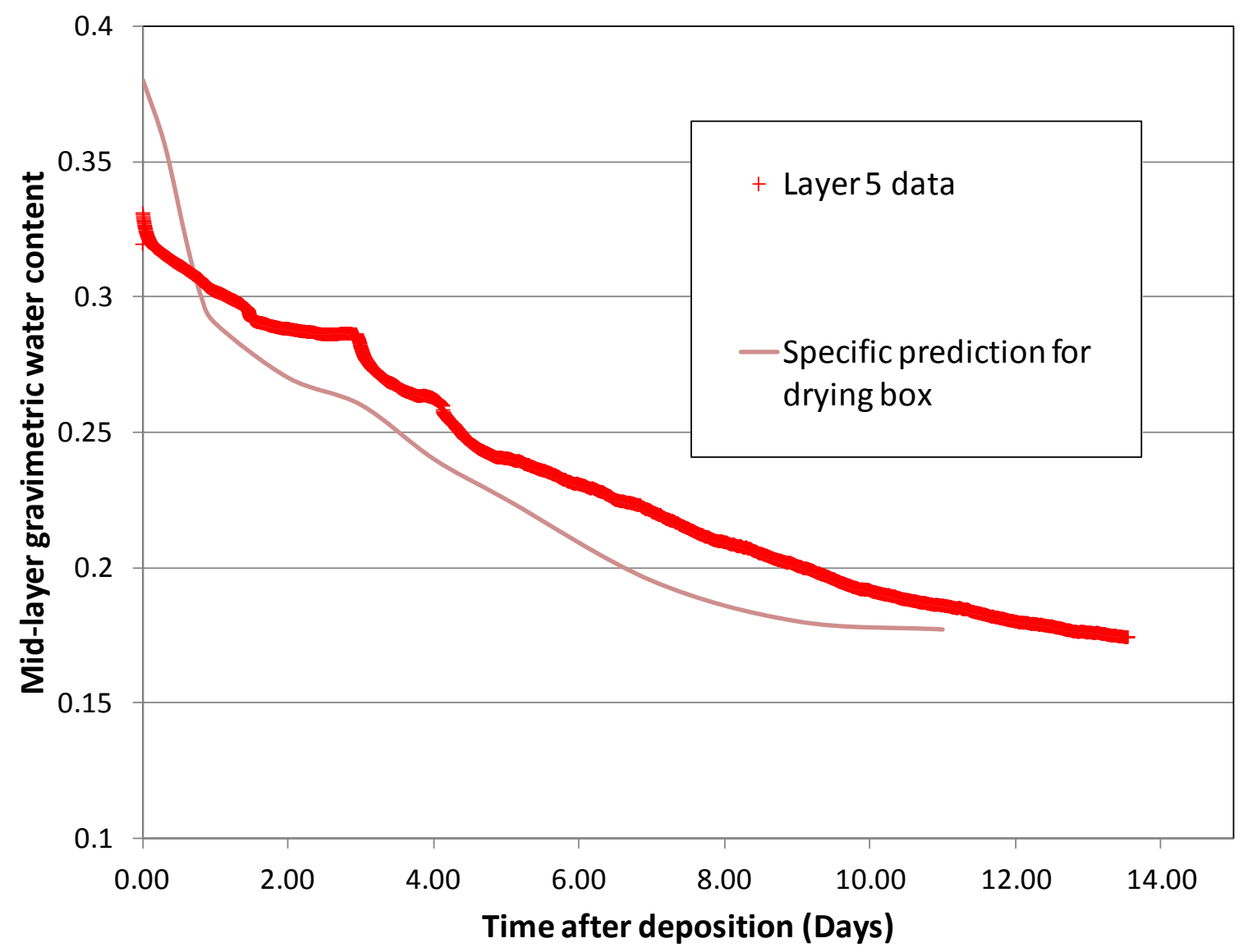

Figure 10 Comparison of predicted and measured midlayer water content in Layer five 


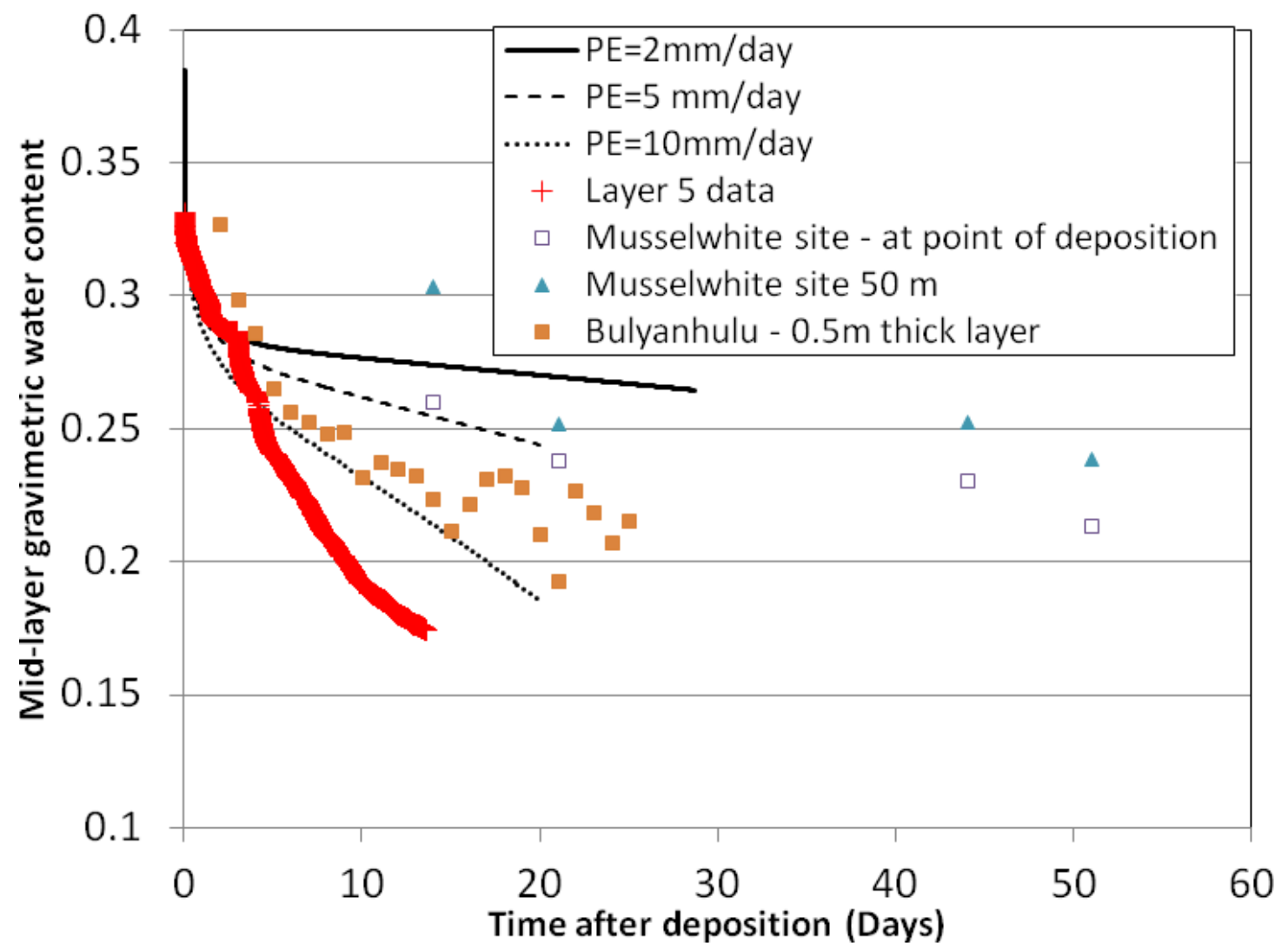

\section{Figure 11 Comparison of generic predictions made in Simms et al. (2010) with field data and Layer five data}

\subsection{Comparison with shear strength behaviour of desiccated-rewet tailings}

The shear strength behaviour of desiccated-rewet tailings in simple shear with a consolidation pressure of $50 \mathrm{kPa}$ and using a vane on unconsolidated specimens is shown in Figures 12 and 13, in terms of the lowest water content experienced during desiccation $\left(w_{d}\right)$. Both sets of data show a breakpoint at about $25 \%$ GWC; in the simple shear test, samples experiencing little or no drying after settling exhibited contractive behaviour, while this is mirrored in the vane strength data with a jump in strength apparent at around $25 \%$ GWC. The void ratio of samples with desiccation history increases at a given consolidation pressure (as presented in the legend of Figure 12). That is, desiccated samples have higher strength, and lower-density, than samples with fewer degrees of desiccation. Desiccation therefore imparts stiffness to the material that is not destroyed during rewetting and consolidation. This was observed even up to consolidation pressures of $400 \mathrm{kPa}$.

The significance of this behaviour is that dewatering to only $25 \%$ may be adequate to prevent remobilisation of underlying layers during deposition. Whether this is adequate to resist earthquake loading is beyond the scope of this paper. However, if $25 \%$ is the required water content, this has considerable implications for drying time. Looking at Figure 11 and considering the case for a potential evaporation (PE) of $10 \mathrm{~mm} /$ day, drying to $25 \%$ instead of $18 \%$ cuts the dewatering time in half. 


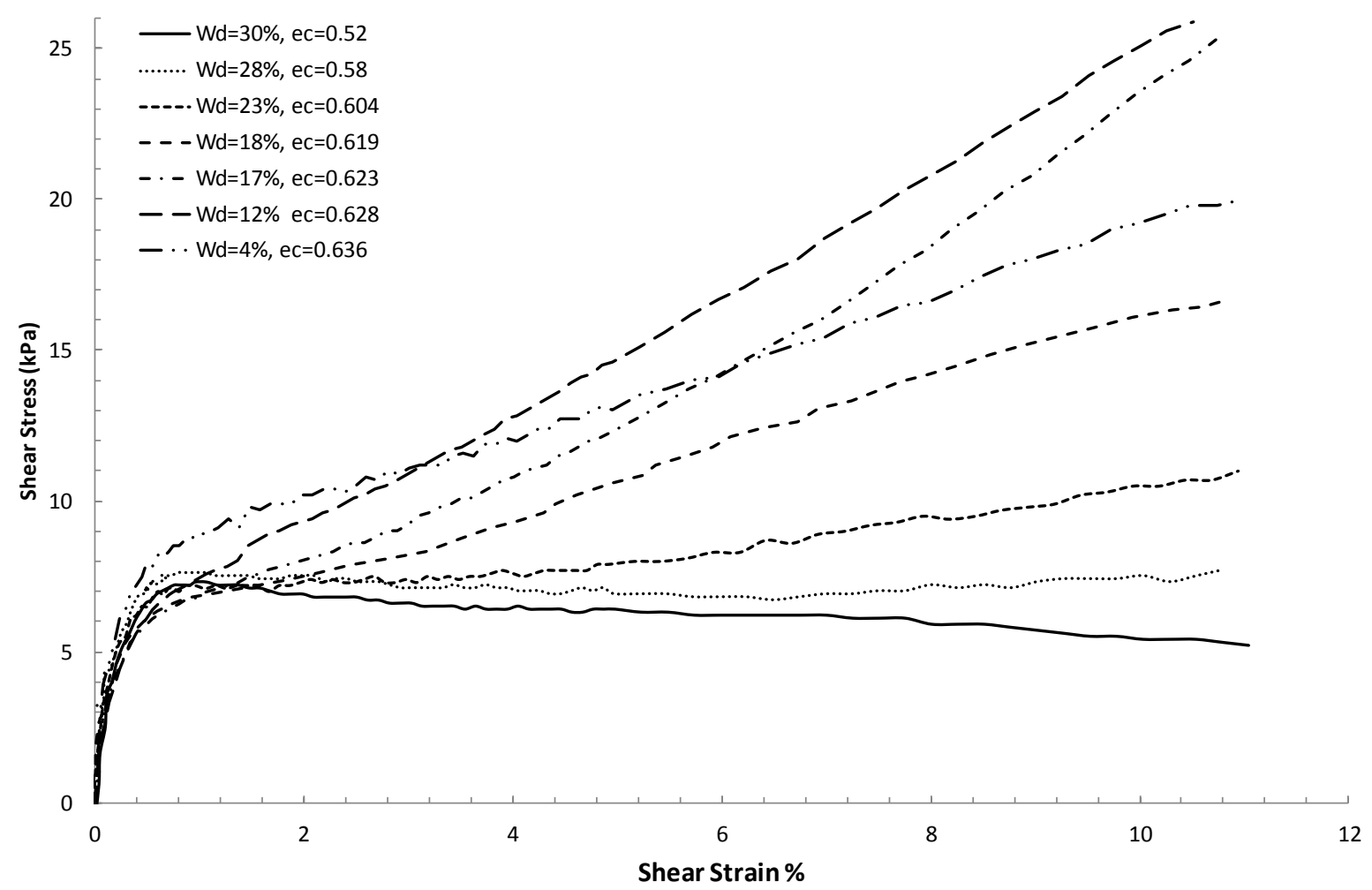

Figure 12 Influence of desiccation history on monotonic shear strength at $50 \mathrm{kPa}$ consolidation pressure in simple shear (Daliri et al., 2011)

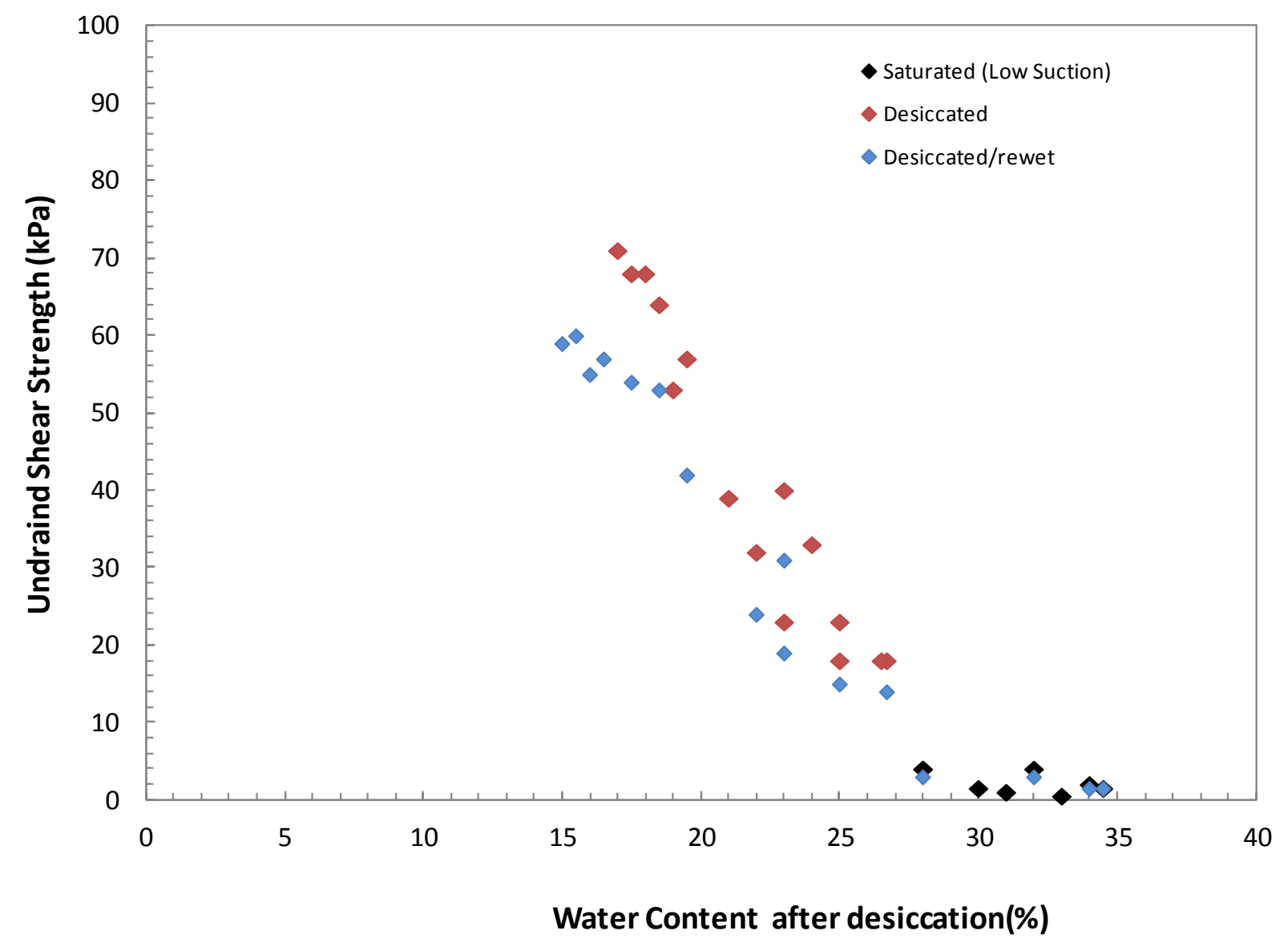

Figure 13 Vane strength data from laboratory simulations of deposition 
We close the paper by considering what would happen if the $25 \%$ GWC was not achieved. Assuming an undrained shear strength of $0.5 \mathrm{kPa}$ or $500 \mathrm{~Pa}$, we examined the slope stability of axi-symmetric tailings stacks using a conventional slope stability software (Geoslope). Figure 14 shows that if little or no desiccation is achieved, the slope stability itself can constrain the beach slope, apart from other constraints such as the self-eroding behaviour. The critical failure surfaces were relatively shallow.

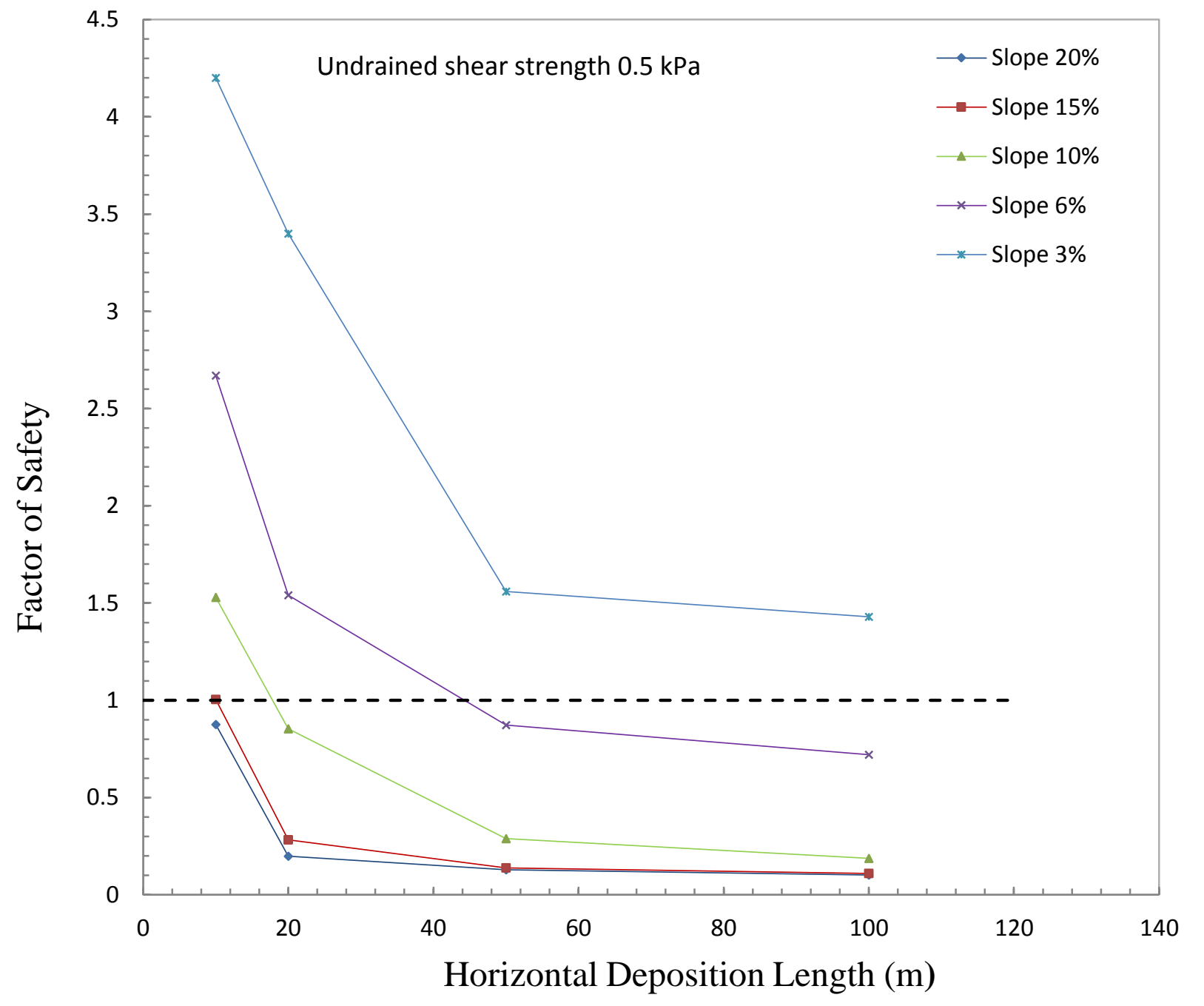

\section{Figure 14 Stability in undrained condition of different sizes of conical tailings deposits simulated in Geoslope, assuming constant undrained strength of $0.5 \mathrm{kPa}$}

\section{Conclusions}

While both the experiments and the generic modelling results show that the dewatering time to achieve a target water content can be increased by water flowing from the older underlying tailings, even a relatively small amount of desiccation can substantially increase strength and change the response from strain softening to strain hardening. The strength increases with desiccation, even though the density after consolidation decreases with decreases. The change in behaviour occurred at around $25 \%$ GWC, substantially higher than the shrinkage limit (18\%). If tailings are not desiccated, the low undrained shear strength may constrain the beach slope.

\section{Acknowledgements}

The support of Golder Associates and of the Natural Science and Engineering Research Council of Canada is gratefully acknowledged. 


\section{References}

Al-Tarhouni, M., Simms, P. and Sivathayalan, S. (2011) Cyclic behaviour of reconstituted and desiccated samples of thickened gold mine tailings, Canadian Geotechnical Journal, Vol. 48, pp. 1044-1060.

Bryan, R., Simms, P. and Verburg, R. (2010) Coupling oxidation to transient drying during multilayer deposition of thickened gold tailings, Minerals Engineering, Vol. 23, pp. 1101-1112.

Cooper, R.A. and Smith, M.E. (2011) Case study - operation of three paste disposal facilities, in Proceedings 14th International Seminar on Paste and Thickened Tailings (Paste2011), R.J. Jewell and A.B. Fourie (eds), 5-7 April 2011, Perth, Australia, Australian Centre for Geomechanics, Perth, pp. 261-270.

Daliri, F., Simms, P. and Sivathayalan, S. (2011) A comparison of different laboratory techniques to simulate stress and moisture history of hard rock mine tailings, in Proceedings of Tailings and Mine Waste 2011 Conference, 7-11 November, Vancouver, Canada, pp. 163-175.

Fisseha, B., Bryan, R. and Simms, P. (2010) Evaporation, unsaturated flow, and salt accumulation in multilayer deposits of a paste gold tailings, ASCE Journal of Geotechnical and Geoenvironmental Engineering, Vol. 136, pp. 1703-1712.

Kam, S., Girard, J., Hmidi, N., Yao, Y. and Longo, S. (2011) Thickened tailings disposal at the Musselwhite Mine, in Proceedings 14th International Seminar on Paste and Thickened Tailings (Paste2011), R.J. Jewell and A.B. Fourie (eds), 5-7 April 2011, Perth, Australia, Australian Centre for Geomechanics, Perth, pp. 225-236.

Kim, H., Daliri, F., Simms, P. and Sivathayalan, S. (2011) The influence of desiccation and overconsolidation on monotonic and cyclic shear response of thickened gold tailings, in Proceedings of the 64th Canadian Geotechnical Conference, Toronto, Ontario, Canada, October 2011, CD-ROM.

McPhail, G. and Brent, C. (2007) Osborne high density discharge - an update from 2004, in Proceedings Tenth International Seminar on Paste and Thickened Tailings (Paste07), A.B. Fourie and R.J. Jewell (eds), 13-15 March 2007, Perth, Australia, Australian Centre for Geomechanics, Perth, pp. 339-350.

Mizani, S., He, L. and Simms, P. (2010) "Out of Pipe" dewatering of thickened tailings during deposition, in Proceedings 13th International Seminar on Paste and Thickened Tailings (Paste2010), R.J. Jewell and A.B. Fourie (eds), 3-6 May 2010, Toronto, Canada, Australian Centre for Geomechanics, Perth, pp. 393-402.

Simms, P. and Grabinsky, M.W. (2004) A simple method for estimating rates of drying and desaturation of paste tailings during surface deposition, in Proceedings of Tailings and Mine Waste 2004, October, Vail, U.S.A., pp. 287-292.

Simms, P., Dunmola, A., Fisseha, B. and Bryan, R. (2010) Generic modelling of desiccation for cyclic deposition of thickened tailings to maximize density and to minimize oxidation, in Proceedings 13th International Seminar on Paste and Thickened Tailings (Paste2010), R.J. Jewell and A.B. Fourie (eds), 3-6 May 2010, Toronto, Canada, Australian Centre for Geomechanics, Perth, pp. 293-301.

Simms, P., Grabinsky, M.W. and Zhan, G. (2007) Modelling evaporation of paste tailings from the Bulyanhulu mine, Canadian Geotechnical Journal, Vol. 44, pp. 1417-1432. 